\title{
Selective inhibition of amine oxidases differently potentiate the hypophagic effect of benzylamine in mice
}

\author{
Grazia Banchelli, Carla Ghelardini, Laura Raimondi, Nicoletta Galeotti, Renato Pirisino* \\ Department of Preclinical and Clinical Pharmacology, University of Florence, Viale Pieraccini 6, 50134 Florence, Italy
}

Received 21 September 2000; received in revised form 29 December 2000; accepted 3 January 2001

\begin{abstract}
In mice deprived of food for 12 h, the i.c.v. or i.p. administration of benzylamine, a substrate common to both monoamine oxidase B and semicarbazide-sensitive benzylamine oxidases, dose-dependently inhibited feeding. This effect was significantly potentiated by selective monoamine oxidase A and B inhibition, suggesting that central monoamines, known to be substrates of these enzymes may be released. The i.p. administration of semicarbazide-sensitive benzylamine oxidase inhibitors, B24 (3,5-ethoxy-4-aminomethylpyridine) and MDL 72274 ((E)-2-phenyl-3-chloroallylamine) strongly potentiated the effect of i.p. but not i.c.v.-administered benzylamine. The hypophagic effect of benzylamine was evaluated following i.c.v. administration, in comparison with the effect of the sympathomimetic compound amphetamine or the $\mathrm{K}^{+}$channel blocker tetraethylammonium, as reference compounds. Our results make it possible to define benzylamine as a centrally acting hypophagic compound devoid of amphetamine-like motor stimulatory effects and point to a role of B24 and MDL 72274 as specific peripheral enhancers of the pharmacological effects of benzylamine. (C) 2001 Elsevier Science B.V. All rights reserved.
\end{abstract}

Keywords: Food consumption; Anorectic activity; Monoamine oxidase A; Monoamine oxidase B; Semicarbazide-sensitive benzylamine oxidases; 5- $\mathrm{HT}_{1 \mathrm{~A}}$ receptor; MDL 72274; B24; WAY 100635

\section{Introduction}

The metabolism of monoamines in mammalian tissues is catalyzed by different amine oxidases, among which monoamine oxidase (amine:oxygen oxidoreductase; EC 1.4.3.4) and semicarbazide-sensitive benzylamine oxidases (EC 1.4.3.6). Monoamine oxidases are found as A or B isoenzymes, each one with different affinities for substrates and sensitivity to inhibitors. Monoamine oxidase A is selectively inhibited by clorgyline, and preferentially metabolizes noradrenaline, tyramine and 5-hydroxytryptamine (5-HT). Monoamine oxidase B deaminates the biogenic amines $\beta$-phenylethylamine, dopamine or benzylamine and is selectively inhibited by L-deprenyl (Knoll, 1998).

Tissue semicarbazide-sensitive benzylamine oxidases are copper-containing enzymes which deaminate endoge-

\footnotetext{
* Corresponding author. Tel.: +39-55-4271-209; fax: +39-55-4271280.

E-mail address: pirisino@server1.pharm.unifi.it (R. Pirisino).
}

nous and exogenous monoamines, and share the xenobiotic substrate benzylamine (Buffoni, 1995) with monoamine oxidase B. Little is known at present of the physiological role of semicarbazide-sensitive benzylamine oxidases. Because these enzymes are present in brain microvessels (Lewinson et al., 1978; Buffoni, 1993; Castillo et al., 1998) in plasma and peripheral vascular tissues, it has been suggested that they might have a protective role against toxic monoamines absorbed exogenously. Conversely, it has been established that semicarbazide-sensitive benzylamine oxidases could have a role in the cardiovascular damage induced by aldehydes deriving from the oxidative deamination of allylamine (Boor and Nelson, 1980; Ramos et al., 1988) or methylamine (Yu and Dong-mei Zuo, 1993; Deng and Boomsma, 1998).

Highly selective and potent semicarbazide-sensitive benzylamine oxidase inhibitors are presently available, among which are the competitive and reversible 3,5ethoxy-4-aminomethylpyridine (B24) (Banchelli et al., 1990), and the non-competitive and irreversible $(E)-2$ phenyl-3-chloroallylamine (MDL 72274) (Lyles et al., 1987; Banchelli et al., 1994). By using a compound struc- 
turally related to MDL 72274 , it has been demonstrated that some pharmacological effects of benzylamine in the isolated arterial bed could be potentiated (Elliot and Callingham, 1991), confirming that selective inhibitors of semicarbazide-sensitive benzylamine oxidases may be important tools for clarifying the role of these enzymes. However, so far, most pharmacological results with selective inhibitors have been obtained in "in vitro" experiments, while pharmacological evidence regarding the role of semicarbazide-sensitive benzylamine oxidase enzymes "in vivo" is scarce.

Feeding behavior is a central function that is profoundly affected by different neurotransmitters, including dopamine and 5-HT (Abdallah et al., 1976; Moreley and Levine, 1985; Parada et al., 1992; Curzon et al., 1997). It is well-known that indirectly acting compounds, with different mechanisms of action, can profoundly influence this function. For example, indirectly acting drugs, such as the dopamine-releasing agent, amphetamine or the 5-HT releasing agent, fenfluramine (Cole, 1978; Aulakh et al., 1988; Parada et al., 1992), act as central anorectic compounds by increasing the release of dopamine or 5-HT respectively. On the other hand, $\mathrm{K}^{+}$channel blockers can reduce feeding behavior (Ghelardini et al., 1997), and induce the central release of dopamine or 5-HT acting as depolarizing compounds in the neurons (Cook and Quast, 1990; Dawson and Routledge, 1995; Schechter, 1997).

Recently, we have observed that benzylamine and some related compounds stimulate sympathetic rat vas deferens neurotransmission and potentiate memory in the mouse. In their activity, they resemble the indirectly acting compound, amphetamine, or the $\mathrm{K}^{+}$channel blocker, tetraethylammonium (Pirisino et al., 1993; Banchelli et al., 2000). Therefore, to clarify the role of semicarbazide-sensitive benzylamine oxidase enzymes in the modulation of the central stimulating activity of benzylamine, we decided to assess the effect of this compound on feeding behavior in mice. In the present work, we compared the activity of benzylamine to that of tetraethylammonium and amphetamine. To evaluate the central or peripheral role of the various classes of amine oxidases in modulating the activity of these compounds, we decided to administer them as i.c.v. or i.p. injections in animals pretreated with the semicarbazide-sensitive benzylamine oxidase inhibitors, B24 and MDL 72274, or with clorgyline and deprenyl, in order to selectively inhibit monoamine oxidase A and B, respectively.

\section{Materials and methods}

\subsection{Animals}

Male Swiss albino mice (23-30 g) from the Morini (San Polo d'Enza, Italy) breeding farm were used. Fifteen mice were housed per cage. The cages were placed in the room of the experiment $24 \mathrm{~h}$ before the test for adaptation. The animals were kept at $23 \pm 1{ }^{\circ} \mathrm{C}$ with a $12 \mathrm{~h}$ light-dark cycle, lights on at 7:00 a.m., and were fed a standard laboratory diet with water ad libitum. All experiments were carried out in accordance with the European Communities Council Directive of 24 November 1986 (86/609/ EEC) for experimental animal care.

\subsection{Tissue samples to assess AO inhibition}

To obtain selective inhibition of monoamine oxidase A and $\mathrm{B}$ activities in mouse brain, we administered 2.5 $\mathrm{mg} / \mathrm{kg}$ i.p. clorgyline or $10 \mathrm{mg} / \mathrm{kg}$ deprenyl (Finnegan et al., 1995). With regard to the dosage regimen of MDL 72274 as selective inhibitor of semicarbazide-sensitive benzylamine oxidases, the same dosage ( $2.5 \mathrm{mg} \mathrm{kg}^{-1}$ i.p.) previously found to be selective for these enzymes in rats was given i.p. to the mice (Banchelli et al., 1994).

Three hours after the injection of saline, clorgyline, deprenyl or MDL 72274 the mice were killed and the brains and the epidydimal white adipose tissue were removed and stored at $-70^{\circ} \mathrm{C}$ for monoamine oxidase $\mathrm{A}$ and $\mathrm{B}$ and semicarbazide-sensitive benzylamine oxidase assay. The homogenates were prepared in 10 volumes of $\mathrm{K}-\mathrm{Na}$ phosphate buffer 0.1 M (pH 7.4), using a hand-held ground glass homogenizer.

\subsection{Amine oxidase activity}

The assay samples contained $50 \mu 1$ homogenate, $50 \mu 1$ buffer and $50 \mu \mathrm{l}$ radioactive substrate. Homogenates were preincubated for $20 \mathrm{~min}$ at $37^{\circ} \mathrm{C}$ prior to substrate addition. Mixtures containing substrate were then incubated at $37^{\circ} \mathrm{C}$ for $10 \mathrm{~min}$, to ensure the linear formation of metabolites. Assays were stopped with $50 \mu 13 \mathrm{~N} \mathrm{HCl}$, and radiolabelled metabolites were extracted into $0.7 \mathrm{ml}$ ethyl acetate; some $(0.5 \mathrm{ml})$ of this extract was counted in a Packard 1900 TR liquid scintillator. Monoamine oxidase A and B activities were determined by using $\left[{ }^{14} \mathrm{C}\right] 5$-HT and $\left[{ }^{14} \mathrm{C}\right]$ benzylamine $0.5 \mathrm{mM}$, respectively, as specific substrates for these enzymes. Semicarbazide-sensitive benzylamine oxidase activity was assayed by using $\left[{ }^{14} \mathrm{C}\right]$ benzylamine $20 \mu \mathrm{M}$ in the presence of high-concentration deprenyl (1 $\mathrm{mM}$ ) to inhibit monoamine oxidase activity. Enzymatic activity was expressed as the amount of product formed per hour per gram of tissue wet weight.

\subsection{Intracerebroventricular injection technique}

Intracerebroventricular (i.c.v.) administration was performed under ether anesthesia, according to the method described by Haley and McCormick (1957). Briefly, during anesthesia, the mice were grasped firmly by the loose skin behind the head. A $0.4-\mathrm{mm}$ external diameter hypodermic needle attached to a $10-\mu l$ syringe was inserted perpendicularly through the skull, no more than $2 \mathrm{~mm}$ into 
the brain of the mouse, where $5 \mu 1$ was then administered. The injection site was $1 \mathrm{~mm}$ to the right or left from the midpoint, on a line drawn through to the anterior base of the ears. Drugs were injected randomly into the right or left ventricle. To ascertain that the drugs were administered exactly into the cerebral ventricle, some mice were injected with $5 \mu l$ of 1:10 diluted India ink and their brains were examined macroscopically after sectioning.

\subsection{Evaluation of food consumption}

The mice were food-deprived for $12 \mathrm{~h}$, although water was available ad libitum. A weighed amount of food (standard laboratory pellets) was given, and the weight consumed (evaluated as the difference between the original amount and the food left in the cage, including spillage) was measured 15, 30, 45 and 60 min after injection, with an accuracy of $0.1 \mathrm{~g}$. An arbitrary cut-off time of $60 \mathrm{~min}$ was used.

\subsection{Rota rod test}

The apparatus consisted of a base platform and a rotating rod with a diameter of $3 \mathrm{~cm}$ and a non-skid surface. The rod was placed at a height of $15 \mathrm{~cm}$ from the base. The rod, $30 \mathrm{~cm}$ in length, was divided into five equal sections by six disks. Then, up to five mice were tested simultaneously on the apparatus, with a rod rotation speed of $16 \mathrm{rpm}$. The integrity of motor coordination was assessed on the basis of the number of falls from the rod in $30 \mathrm{~s}$, in accordance with Vaught et al. (1985). Performance time was measured before and 15, 30, 45 and $60 \mathrm{~min}$ after the i.c.v. administration of saline or drug solutions.

\subsection{Drugs}

Deprenyl hydrochloride, clorgyline hydrochloride, benzylamine hydrochloride, amphetamine sulfate, tetraethylammonium $\mathrm{HCl}$, Ro 16-6491 [ $N$-(2-aminoethyl)-p-chlorobenzamide $\mathrm{HCl}]$ and $\alpha$-methyl- $p$-tyrosine methyl ester were purchased from Sigma (St. Louis, MO, USA). WAY $100635\{N$-[4-(2-methoxyphenyl)-1-piperazinyl]- $N$-(2pyridinyl) cyclo-hexanecarboxamide\} was obtained from RBI Sigma/Aldrich, Milan. $\left[7_{-}{ }^{14} \mathrm{C}\right]$ benzylamine hydrochloride $\left(57 \mathrm{mCi} \mathrm{mmol}^{-1}\right)$ and 5-hydroxy $\left[2{ }^{14} \mathrm{C}\right]$ tryptamine $\left(50 \mathrm{mCi} \mathrm{mmol}^{-1}\right)$ were obtained from Amersham Pharmacia Biotech Italia (20138 Milan). MDL 72274 was a gift of the Marion Merrell Dow Research Institute (Strasbourg Cedex, France). B24 was synthesized by Prof. V. Bertini (Department of Organic Chemistry of the University of Genoa).

The drugs were dissolved in isotonic $(\mathrm{NaCl} 0.9 \%)$ saline solution and their $\mathrm{pH}$ value was checked; drug concentrations were prepared in such a way that the necessary dose could be administered in a volume of $5 \mu \mathrm{l} /$ mouse by i.c.v. injection and $10 \mathrm{ml} \mathrm{kg}{ }^{-1}$ by i.p. injection.

\subsection{Statistical analysis}

All experimental results are expressed as the means \pm S.E.M. Analysis of variance (ANOVA), followed by Fisher's Protected Least Significant Difference (PLSD) procedure for posthoc comparison, were used to verify the significance of differences between two means. Data were analyzed using the StatView software for the Macintosh (1992). Fitting of the sigmoid dose-response curves, as well as $\mathrm{ED}_{50}, K_{\mathrm{m}}$ and $V_{\text {max }}$, were obtained from a non-linear regression analysis (Prism program, GraphPad Software, San Diego, CA).

\section{Results}

\subsection{Amine oxidase inhibition}

Because of the lack of information on the inhibitory effect of MDL 72274 on semicarbazide-sensitive benzylamine oxidase activity in mice, its inhibition kinetics were studied in the epidydimal white adipose tissue. In this tissue, MDL 72274 showed $\mathrm{IC}_{50}$ values very similar to those previously observed in rats $\left(1.7 \times 10^{-8}\right.$ and $2 \times 10^{-9}$ $\mathrm{M}$ in mice and rats respectively; $n=5$ ). The apparent $K_{\mathrm{m}}$ values of semicarbazide-sensitive benzylamine oxidase-dependent oxidative deamination of $\left[{ }^{14} \mathrm{C}\right]$ benzylamine did not vary in the controls and in MDL 72274-treated homogenates $(63 \pm 10$ and $58 \pm 14 \mu \mathrm{M}$, respectively); on the contrary $V_{\max }$ values were significantly reduced in control and in MDL 72274-treated samples (43 \pm 5 and $\left.20 \pm 5 \mathrm{nmol} \mathrm{mg}{ }^{-1} \mathrm{~min}^{-1} ; P<0.05\right)$. Together these results confirm that this inhibitor has similar activity in mouse and rat semicarbazide-sensitive benzylamine oxidases (Banchelli et al., 1994).

In order to ascertain whether a selective amine oxidase inhibition was obtained in mice during experiments on feeding behavior, we assayed monoamine oxidase A, B and semicarbazide-sensitive benzylamine oxidases in the whole brain homogenates of these animals. After the i.p. administration of MDL 72274, both monoamine oxidase A and $\mathrm{B}$ activities were unaffected (Fig. 1), while clorgyline and deprenyl inhibited these enzymes by $92 \%$ and $93 \%$, respectively. A very low activity of semicarbazide-sensitive benzylamine oxidases in the mouse brain homogenates was measured which probably was due to microvessels (Castillo et al., 1998). Under these conditions, however, the deamination of $\left[{ }^{14} \mathrm{C}\right]$ benzylamine, still present after high deprenyl concentrations $(1 \mathrm{mM})$, was significantly reduced (controls $=92.8 \pm 13 \mathrm{nmol} \mathrm{g}^{-1} \mathrm{~h}^{-1}$; MDL 72274-pretreated $=49.3 \pm 11 \mathrm{nmol} \mathrm{g}^{-1} \mathrm{~h}^{-1} ; P<0.05$; $n=6$ ) in the presence of MDL 72274 pretreatment. To further confirm the inhibitory effect of MDL 72274 in vivo, we studied the effect of this compound in the epidydimal white adipose tissue homogenates, a tissue known to be particularly rich in semicarbazide-sensitive benzylamine 


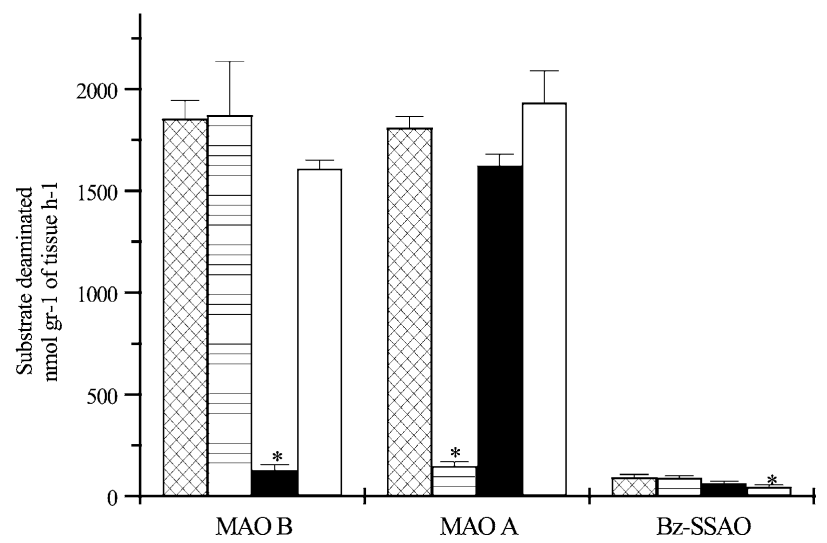

Fig. 1. Effect of a single i.p. injection of either saline, deprenyl $(10 \mathrm{mg}$ $\left.\mathrm{kg}^{-1}\right)$, clorgyline $\left(2.5 \mathrm{mg} \mathrm{kg}^{-1}\right)$ or MDL $72274\left(2.5 \mathrm{mg} \mathrm{kg}{ }^{-1}\right)$ on monoamine oxidase $\mathrm{B}$ (MAO B), monoamine oxidase A (MAO A) and semicarbazide-sensitive benzylamine oxidase (Bz-SSAO) activity in mouse brain. The brains were removed and stored at $-70^{\circ} \mathrm{C} 2 \mathrm{~h}$ after the injection, when the food consumption tests were completed. Values are the means \pm S.E.M. of six experiments carried out in duplicate. Differences between groups were analyzed by Student's paired two-tailed $t$-test. ${ }^{*}{ }^{*} P<0.001,{ }^{*} P<0.05$ compared with saline. Control ( clorgy-

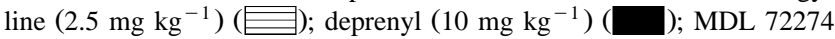
$\left(2.5 \mathrm{mg} \mathrm{kg}^{-1}\right)(\square)$.

oxidases. MDL 72274 reduced semicarbazide-sensitive benzylamine oxidase activity in this tissue up to $85 \%$, thus more significantly than in the brain, (controls $=1238 \pm 7$; MDL 72274 pretreated $=183 \pm 9$ nmol $\mathrm{g}^{-1} \mathrm{~h}^{-1}$; $P<0.01 ; n=6)$.

\subsection{Feeding behavior}

In accordance with the results obtained from previous work (Ghelardini et al., 1997), the 12-h food-deprived mice showed an increase in the amount of food consumed during the $60 \mathrm{~min}$ test $(673 \pm 28 \mathrm{mg} /$ mouse $)$. This result was significantly higher than that from control, non-fooddeprived animals $(240 \pm 14 \mathrm{mg} /$ mouse; $P>0.001 ; n=$ 20). Tetraethylammonium ( $30 \mathrm{nmol} /$ mouse i.c.v. $)$ or benzylamine $(226 \mathrm{nmol} /$ mouse i.c.v.) inhibited the food consumption of 12-h food-deprived mice to about the same extent (Fig. 2). The anorectic effect of tetraethylammonium and benzylamine was comparable to that obtained with $5 \mathrm{nmol}$ amphetamine given i.c.v. to mice.

Fig. 2 illustrates the hypophagic activity of these compounds in the presence of a selective amine oxidase inhibition obtained with clorgyline, deprenyl and MDL 72274 administered i.p., $1 \mathrm{~h}$ before assessment of food consumption. In these experiments, it was previously verified that, as compared to that of the controls, pretreatment with these inhibitors did not substantially affect the food consumption of the animals. It is evident from Fig. 2 that monoamine oxidase A and B inhibition both significantly potentiated the anorectic effect of benzylamine and amphetamine, while only the monoamine oxidase B inhibitor, deprenyl, increased the effect of tetraethylammonium. Similar results were obtained when Ro 16-6491, a selective monoamine oxidase B inhibitor devoid of indirect sympathomimetic activity, was used (data not shown). Since the activity of semicarbazide-sensitive benzylamine oxidases in the whole brain tissues is low, it was perhaps not surprising that the effect of the i.c.v.- injected benzylamine was unaffected by pretreatment with the selective semicarbazide-sensitive benzylamine oxidase inhibitor, MDL 72274.

As shown in Fig. 3, the i.p. pretreatment with deprenyl significantly shifted to the left the dose-response curve for the anorectic effect of benzylamine administered i.c.v., so that the $\mathrm{ED}_{50}$ values ( $\mathrm{CL}=95 \%$ confidence intervals) for this compound were reduced from $151.90(\mathrm{CL}=35.04-$ $658.60)$ to $2.22(\mathrm{CL}=0.58-8.46) \mathrm{nmol} /$ mouse. Monoamine oxidase $\mathrm{B}$ inhibition also decreased the $\mathrm{ED}_{50}$ of amphetamine approximately 10-fold (data not shown).

The ability of semicarbazide-sensitive benzylamine oxidases to control the anorectic effect of benzylamine was also studied in experiments in which this compound was administered i.p. With this route of administration, benzylamine $\left(600 \mathrm{mg} \mathrm{kg}^{-1}\right)$ produced only minimal effects when given alone; however, the MDL 72274 and deprenyl pretreatment or a combination of both, shifted the benzylamine dose-response curve to the left (Fig. 4). In agreement with this the approximated $\mathrm{ED}_{50}$ values of benzylamine were reduced to $173.3,85.2,42.8 \mathrm{mg} \mathrm{kg}^{-1}$ in mice

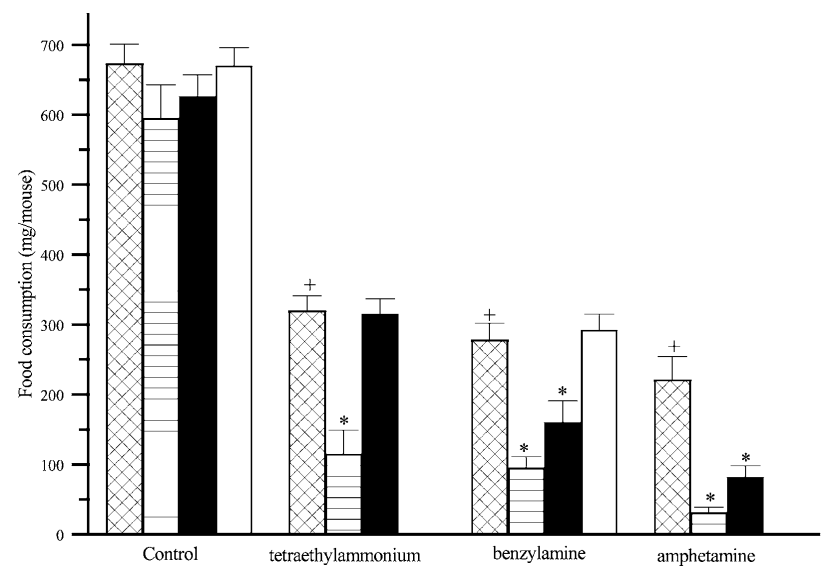

Fig. 2. Effect of selective inhibition of monoamine oxidase A, monoamine oxidase B and semicarbazide-sensitive benzylamine oxidases on food intake of 12-h food-deprived mice after administration of benzylamine $(226 \mathrm{nmol})$, tetraethylammonium $(30 \mathrm{nmol})$ and amphetamine $(5 \mathrm{nmol})$. Mice were i.c.v. injected with saline or drug solution $15 \mathrm{~min}$ before the test. Amine oxidase inhibitors were administered $60 \mathrm{~min}$ before the treatment with drugs. The food intake values were evaluated as the accumulated amount of food eaten $60 \mathrm{~min}$ after the beginning of the test. Vertical lines represent S.E.M.; the number of mice was between 10 and 20. Student's $t$-test, $+P<0.01$ in comparison with saline-treated mice; ${ }^{*} P<0.01$ in comparison with drug-treated mice without selective AO inhibition. Control ( $\left.\mathrm{mg} \mathrm{kg}^{-1}\right)(\square)$; MDL 72274 (2.5 $\left.\mathrm{mg} \mathrm{kg}^{-1}\right)(\square)$. 


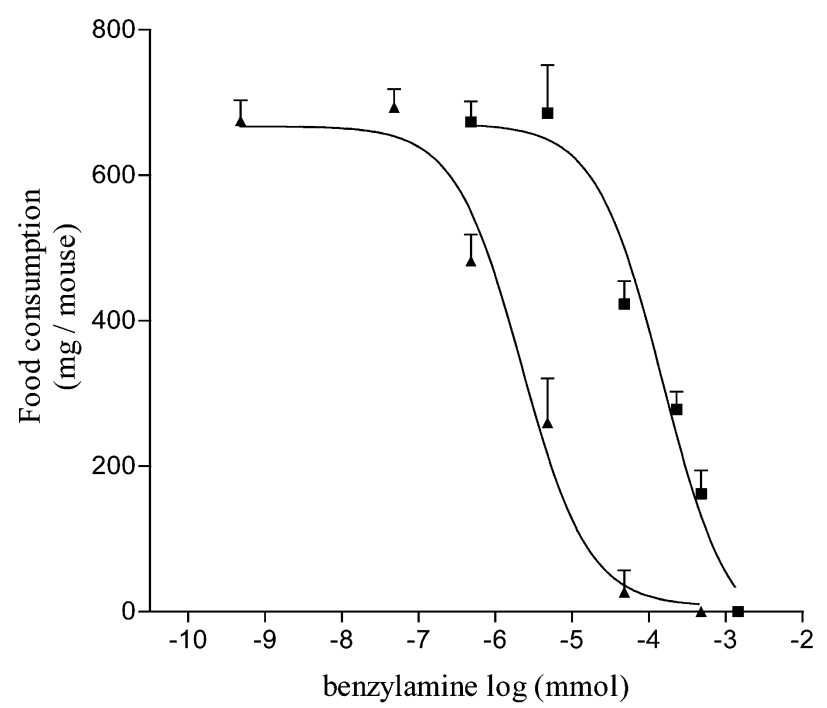

Fig. 3. The selective inhibition of monoamine oxidase B shifted the dose-food consumption curves for i.c.v. injected benzylamine to the left for 12-h food-deprived mice. Benzylamine (- - -$)$; benzylamine + deprenyl $(-\boldsymbol{\Lambda}-)$. Mice were injected with deprenyl $\left(10 \mathrm{mg} \mathrm{kg}^{-1}\right) 1 \mathrm{~h}$ before the test. Each point represents the mean value \pm S.E.M. for $10-20$ mice.

pretreated with MDL 72274, deprenyl and deprenyl + MDL 72274, respectively. In order to confirm the role of

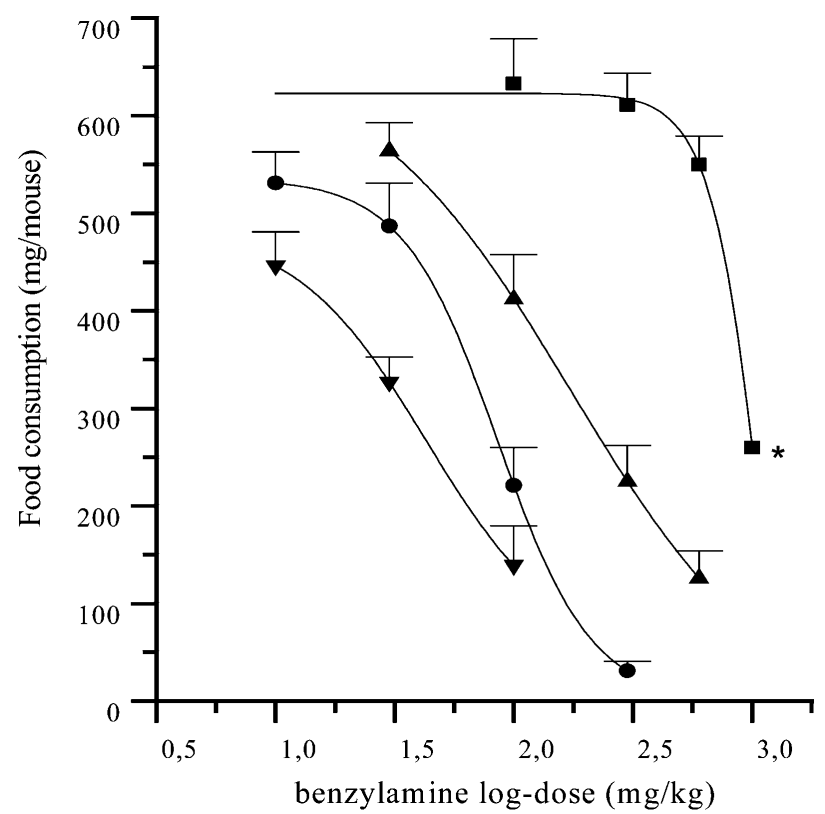

Fig. 4. Selective inhibition of monoamine oxidase B and semicarbazidesensitive benzylamine oxidases shifted the dose-food consumption curves for i.p.-injected benzylamine to the left for 12-h food-deprived mice. Control (- - -); deprenyl (10 mg kg $\left.{ }^{-1}\right)\left(-\mathbf{O}_{-}\right)$; MDL 72274 (2.5 mg $\left.\mathrm{kg}^{-1}\right)(-\boldsymbol{\Lambda}-)$; deprenyl + MDL $72274(-\mathbf{\nabla}-)$. Mice were i.p. injected with saline or benzylamine solution $15 \mathrm{~min}$ before the test. Amine oxidase inhibitors were administered $60 \mathrm{~min}$ before treatment with benzylamine. Each point represents the mean value \pm S.E.M. for $10-20$ mice. ${ }^{*}$ At this dosage general toxicity and motor incoordination were observed. semicarbazide-sensitive benzylamine oxidase inhibitors in potentiating the pharmacological activity of benzylamine administered peripherally, the effect of B24 $\left(100 \mathrm{mg} \mathrm{kg}^{-1}\right.$ i.p.), another selective inhibitor of these enzymes, structurally unrelated to MDL 72274, was also evaluated. After

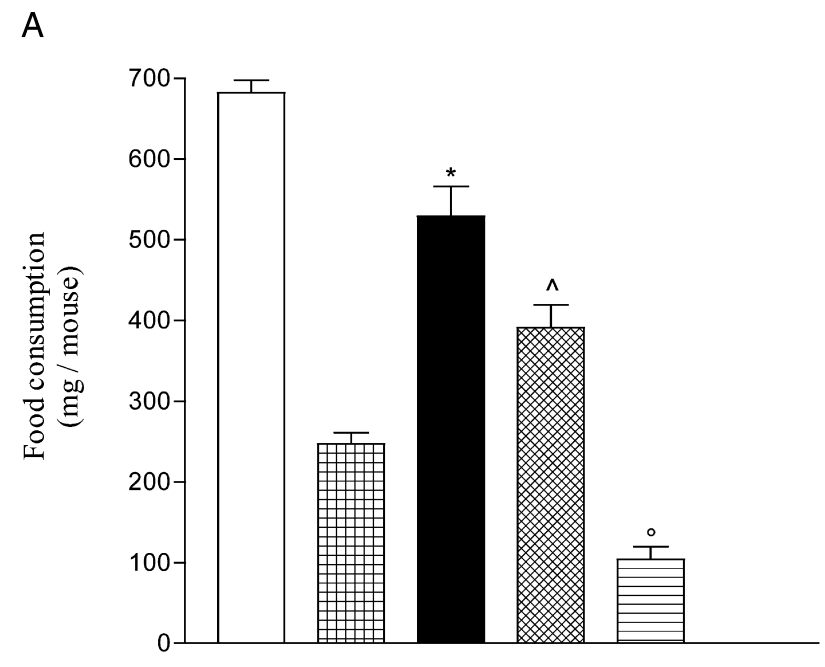

amphetamine $5 \mathrm{nmol}$

B

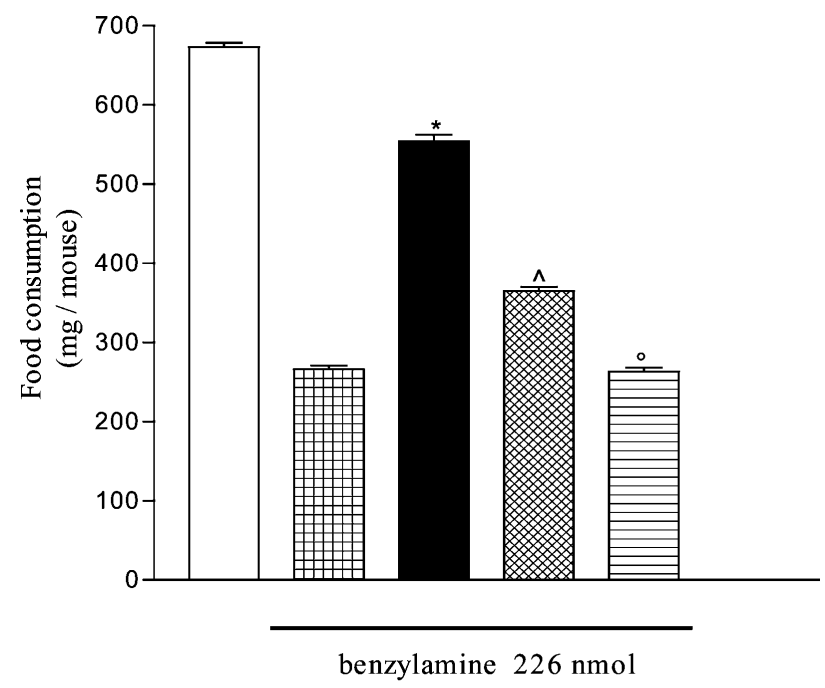

Fig. 5. Modulation of the anorectic effect of amphetamine (A) and benzylamine (B) induced by the 5-HT $\mathrm{HA}_{1 \mathrm{~A}}$ antagonist, WAY 100635 in $\alpha$-methyl- $p$-tyrosine- and clorgyline-pretreated mice. $\alpha$-Methyl- $p$-tyrosine and clorgyline were administered i.p. 2 and $1 \mathrm{~h}$ before the test, respectively. WAY 100635 and amphetamine or benzylamine were given i.c.v. in the same injection. Student's $t$-test, ${ }^{*} P<0.01$ in comparison with amphetamine or benzylamine-treated mice; $P<0.01$ in comparison with amphetamine or benzylamine $+\alpha$-methyl- $p$-tyrosine-treated mice; ${ }^{\circ} \mathrm{P}<$ 0.01 in comparison with amphetamine or benzylamine $+\alpha$-methyl- $p$ tyrosine + clorgyline-treated mice. Control ( $\square$ ); benzylamine or amphetamine alone $(\mathbb{E}) ;+\alpha$-methyl- $p$-tyrosine $(\square)$; + clorgyline $+\alpha$ methyl-p-tyrosine ( clorgyline $+\alpha$-methyl- $p$-tyrosine + WAY 0.8 nmol (㞎). 
Table 1

Effect of benzylamine, amphetamine and other central dopamine and 5-HT modulators in mouse rota-rod test

\begin{tabular}{|c|c|c|c|c|}
\hline \multirow{3}{*}{ Treatment } & \multicolumn{4}{|c|}{ Number of falls in $30 \mathrm{~s}$} \\
\hline & \multirow[t]{2}{*}{ Before treatment } & \multicolumn{3}{|c|}{ After treatment } \\
\hline & & $15 \mathrm{~min}$ & $30 \mathrm{~min}$ & $45 \mathrm{~min}$ \\
\hline Saline (5 $\mu 1$ i.c.v.) & $3.1 \pm 0.3$ & $1.8 \pm 0.3$ & $1.4 \pm 0.2$ & $0.8 \pm 0.2$ \\
\hline Bz (226 nmol i.c.v.) & $2.9 \pm 0.2$ & $1.7 \pm 0.3$ & $1.1 \pm 0.5$ & $1.1 \pm 0.5$ \\
\hline Clorgyline (2.5 $\mathrm{mg} \mathrm{kg}^{-1}$ i.p.) & $3.3 \pm 0.2$ & $2.5 \pm 0.4$ & $1.8 \pm 0.5$ & $1.4 \pm 0.3$ \\
\hline $\operatorname{MDL}\left(2.5 \mathrm{mg} \mathrm{kg}^{-1}\right.$ i.p. $)$ & $3.1 \pm 0.2$ & $2.1 \pm 0.2$ & $1.5 \pm 0.2$ & $1.3 \pm 0.3$ \\
\hline Deprenyl (10 $\mathrm{mg} \mathrm{kg}^{-1}$ i.p.) & $3.2 \pm 0.3$ & $2.6 \pm 0.3$ & $1.3 \pm 0.2$ & $1.1 \pm 0.2$ \\
\hline Deprenyl (10 $\mathrm{mg} \mathrm{kg}^{-1}$ i.p. $)+\mathrm{Bz}\left(300 \mathrm{mg} \mathrm{kg}^{-1}\right.$ i.p. $)$ & $3.3 \pm 0.3$ & $2.3 \pm 0.5$ & $1.9 \pm 0.3$ & $1.5 \pm 0.2$ \\
\hline Deprenyl (10 $\mathrm{mg} \mathrm{kg}^{-1}$ i.p.) $+\mathrm{Bz}$ (226 nmol i.c.v.) & $3.0 \pm 0.2$ & $2.2 \pm 0.5$ & $0.8 \pm 0.2$ & $0.9 \pm 0.2$ \\
\hline $\begin{array}{l}\left.\text { Deprenyl (10 mg kg }{ }^{-1} \text { i.p. }\right)+\operatorname{MDL}\left(2.5 \mathrm{mg} \mathrm{kg}^{-1} \text { i.p. }\right)+ \\
\text { Bz (100 } \mathrm{mg} \mathrm{kg}^{-1} \text { i.p.) }\end{array}$ & $2.5 \pm 0.3$ & $2.1 \pm 0.4$ & $0.9 \pm 0.2$ & $0.5 \pm 0.2$ \\
\hline AMPH (5 nmol i.c.v.) & $2.4 \pm 0.3$ & $3.1 \pm 0.3^{\mathrm{a}}$ & $3.3 \pm 0.4^{\mathrm{a}}$ & $2.7 \pm 0.4^{\mathrm{a}}$ \\
\hline Deprenyl (10 $\mathrm{mg} \mathrm{kg}^{-1}$ i.p.) + AMPH (5 nmol i.c.v.) & $2.2 \pm 0.3$ & $3.9 \pm 0.4^{\mathrm{a}, \mathrm{b}}$ & $4.2 \pm 0.4^{\mathrm{a}, \mathrm{b}}$ & $3.8 \pm 0.4^{\mathrm{a}, \mathrm{b}}$ \\
\hline $\begin{array}{l}\alpha-\operatorname{MpT}\left(100 \mathrm{mg} \mathrm{kg}^{-1} \text { i.p. }\right)+\text { clorgyline }\left(2.5 \mathrm{mg} \mathrm{kg}^{-1} \text { i.p. }\right)+ \\
\text { AMPH (5 nmol i.c.v.) }\end{array}$ & $3.1 \pm 0.5$ & $2.8 \pm 0.4^{\mathrm{b}}$ & $1.7 \pm 0.5^{\mathrm{b}}$ & $0.6 \pm 0.5^{\mathrm{b}}$ \\
\hline
\end{tabular}

$\mathrm{AMPH}=$ amphetamine, $\mathrm{Bz}=$ benzylamine, $\alpha-\mathrm{MpT}=\alpha$-methyl- $p$-tyrosine, $\mathrm{MDL}=\mathrm{MDL} 72274$. Each value represents the mean for $8-10$ mice.

${ }^{\mathrm{a}} P<0.01$ in comparison with saline controls.

${ }^{\mathrm{b}} P<0.05$ in comparison with AMPH - treated mice.

i.p. administration of benzylamine $\left(300 \mathrm{mg} \mathrm{kg}^{-1}\right)$, food consumption was reduced from $624 \pm 19$ to $225 \pm 37$ and $321 \pm 31 \mathrm{mg} /$ mouse in MDL 72274 and B24-pretreated mice, respectively.

\subsection{Pharmacological characterization of hypophagic ef- fect of benzylamine}

To gain more information on the nature of the neurotransmitters involved in the effect of benzylamine, we compared its anorectic activity to that of amphetamine in the presence of some pharmacological manipulations. Pretreatment with $\alpha$-methyl-p-tyrosine $100 \mathrm{mg} \mathrm{kg}^{-1}$ i.p., $2 \mathrm{~h}$ before the experiments, so as to decrease central catecholaminergic activity, significantly reduced $(61 \%)$, but did not abolish, the effect of 5 nmol i.c.v. amphetamine (Fig. 5A). Remarkably, under these conditions, the residual anorectic activity of amphetamine was potentiated $(77 \%)$ by pretreatment of the animals with the monoamine oxidase A inhibitor, clorgyline.

When the selective 5- $\mathrm{HT}_{1 \mathrm{~A}}$ receptor antagonist, WAY 100635 (0.8 nmol), was co-administered with amphetamine, a significant potentiation of the anorectic effect of $5 \mathrm{nmol}$ i.c.v. amphetamine in mice pretreated with $\alpha$-methyl- $p$-tyrosine + clorgyline was observed, whereas the $5-\mathrm{HT}_{3}$ (Ondansetron) or 5- $\mathrm{HT}_{4}$ [1-[2(methylsulphonyl)amimo]ethyl-4-piperidinyl]methyl-5-fluoro-2-methoxy$1 \mathrm{H}$-indole-3-carboxylate hydrochloride (GR125487) receptor antagonists were ineffective (data not shown). Treatment with the agonists alone and in combination with $\alpha$-methyl- $p$-tyrosine and clorgyline did not modify the food intake with respect to that of the controls. The same pharmacological treatments, allowed us to modulate the anorexic effect of $226 \mathrm{nmol}$ i.c.v. benzylamine in a similar manner to that of amphetamine (Fig. 5B).

\subsection{Effects of treatments on mouse behavior}

The motor coordination of mice treated with benzylamine, amphetamine, tetraethylammonium and other compounds used in food consumption studies was evaluated. Compared to controls, in the rota rod test (Table 1), benzylamine-treated mice were not impaired as to motor coordination, as seen from the progressive reduction of the number of falls of the animals, which indicated that the mice had learned how to balance on the rotating rod. As expected, the only exception was in the amphetaminetreated group, where a significant, time-related increase in the number of falls was measured. The motor incoordination induced by amphetamine was further potentiated by deprenyl pretreatment, while it was abolished by the simultaneous administration of $\alpha$-methyl- $p$-tyrosine. Similar results were obtained with the hole-board test (data not shown), where again the amphetamine-, but not benzylamine-treated animals, showed an increase in performance which was completely abolished by $\alpha$-methyl- $p$-tyrosine treatment.

\section{Discussion}

These studies provide the first demonstration that benzylamine, a substrate common to monoamine oxidase B and semicarbazide-sensitive benzylamine oxidase enzymes, has anorectic properties in mice which are probably due to the release of central catecholamines and 5-HT. 
The i.c.v. injections of benzylamine dose dependently reduced the food intake in mice deprived of food for $12 \mathrm{~h}$. We injected benzylamine directly into the cerebral ventricles in order to limit the activity to the central nervous system and to exclude the role of peripheral mechanisms. The selective inhibition of monoamine oxidase B significantly potentiated the hypophagic effect of benzylamine about 100 -fold, while, as expected, considering the very low activity of semicarbazide-sensitive benzylamine oxidases in the brain, a similar effect was not detected during pretreatment with the semicarbazide-sensitive benzylamine oxidase inhibitor, MDL 72274. Significant differences from the i.c.v. administration route were observed after i.p. administration of benzylamine. In fact, the hypophagic effect of this compound was progressively potentiated by pretreatment with MDL 72274, deprenyl, or a combination of these two inhibitors. This result showed a clear role of semicarbazide-sensitive benzylamine oxidases, together with monoamine oxidase $\mathrm{B}$, in controlling the effect of peripherally administered benzylamine.

After i.c.v. administration, the inhibition of monoamine oxidase A or B strongly potentiated both the amphetamine or benzylamine hypophagic response, whereas only monoamine oxidase B inhibition significantly increased the effect of tetraethylammonium. Some suggestions could be made in order to explain these effects. It is well known that a variety of neurotransmitters may decrease food intake mainly by acting at the hypothalamic level; among these dopamine and 5-HT, which are substrates of monoamine oxidase B and A, respectively (Moreley and Levine, 1985; Buffoni, 1995; Knoll, 1998), have an important role. It has also been shown that treatment with monoamine oxidase inhibitors could induce anorectic activity in animals by increasing the levels of 5-HT or dopamine in the brain (Gray et al., 1981; Gregory and Smith, 1982; Aulakh et al., 1988). $\mathrm{K}^{+}$channel blockers such as tetraethylammonium or 4-aminopyridine could also increase the release of neurotransmitters (Dawson and Routledge, 1995; Schechter, 1997) and inhibit feeding in mice (Ghelardini et al., 1997). The potentiation induced by deprenyl and the failure of clorgyline to increase the effect of tetraethylammonium suggest that the anorectic activity of this last compound preferentially involves dopaminergic neurons. An attempt to highlight a serotoninergic, clorgyline-sensitive, component of the activity of tetraethylammonium by administering higher dosages $(60 \mathrm{nmol})$ of this compound failed, because of its very strong motor stimulatory activity. Taken together, these considerations can reasonably explain the deprenyl and clorgyline-induced potentiation of the hypophagic effects of tetraethylammonium, amphetamine and benzylamine as the inhibition of oxidative deamination of the neurotransmitters released by these compounds. On the other hand, it is well known that benzylamine (but not tetraethylammonium or amphetamine) is a substrate with good affinity for monoamine oxidase B or semicarbazide-sensitive benzy- lamine oxidase enzymes (Buffoni, 1995). Therefore, the potentiation of the anorectic effect of benzylamine could also be explained partly by the inhibition of oxidative deamination, which leads to an increase in the central concentrations of this compound.

In our experiments, we used deprenyl to selectively inhibit monoamine oxidase B activity. It is well known that this inhibitor is metabolized in vivo to L-amphetamine derivatives (Knoll, 1998), which in turn should be responsible for the potentiation of the anorectic activity observed in our experiments. However, at the dosage utilized, deprenyl, clorgyline or MDL72274 alone did not reduce the food consumption of the animals. A similar potentiation of the anorectic effect of benzylamine was also observed in animals pretreated with Ro 16-6491, a selective monoamine oxidase B inhibitor (Alemany et al. 1995) devoid of amphetamine-like activity, as well as with B24, a pyridine-derived, semicarbazide-sensitive benzylamine oxidase inhibitor. This confirms that these effects were actually due to a selective amine oxidases inhibition, and were unrelated to the chemical structure of the inhibitors.

As mentioned before, the potentiation of the anorectic activity of amphetamine, after monoamine oxidase A or B inhibition, suggests that the effect of these compounds is probably linked to release of both dopamine and 5-HT. Notwithstanding the fact that amphetamine is generally regarded as an indirect dopaminergic compound, results of studies combining microdialysis in the lateral hypothalamus with simultaneous infusion of amphetamine suggest that serotoninergic mechanisms could also play a role. A significant increase in the central levels of both dopamine and 5-HT has been shown after amphetamine administration to experimental animals; a good correlation was established between the anorectic activity of amphetamine and the hypophagic effect induced by direct i.c.v. injections of these two neurotransmitters (Parada et al, 1988, 1992). On the other hand, the observation that, in mice and rats, 2- or 4-h pretreatment with $\alpha$-methyl- $p$-tyrosine failed to antagonize or incompletely antagonized the anorectic effect of amphetamine may be explained by an inadequate depletion of central catecholamines, and also by the release of non-catecholaminergic neurotransmitters (Abdallah et al., 1976; Shucla et al., 1990).

Investigations into the mechanism of the anorectic action of our compounds, by direct measurement of monoamine levels in the brain, surpassed the aim of the present work which was mainly oriented at investigating the behavioral effects of selective amine oxidase inhibition. However, a pharmacological characterization of the effects induced by benzylamine in comparison with amphetamine was made in this work. Somatodendritic $5-\mathrm{HT}_{1 \mathrm{~A}}$ receptors in the raphe nuclei appear to play an important role in controlling the hypophagic effect of different serotoninergic compounds. For example, recent findings have established that blockade of $5-\mathrm{HT}_{1 \mathrm{~A}}$ receptors with selective antagonists facilitates the effect of the indirectly acting 
compounds, fenfluramine and fluoxetine, by means of a rise in extracellular 5-HT (Grignaschi, 1998). On the contrary, reversal of anorexia induced by these compounds has been obtained using the selective $5-\mathrm{HT}_{1 \mathrm{~A}}$ receptor agonist, 8-hydroxy-2-(di-n-propylamino) tetralin (Currie et al., 1998).

In our experiments, $100 \mathrm{mg} \mathrm{kg}^{-1}$ i.p. $\alpha$-methyl-p-tyrosine given $2 \mathrm{~h}$ before the tests (a dosage which did not modify basal food consumption) significantly reduced the anorectic effect of amphetamine and benzylamine. The residual effect was potentiated by clorgyline and further increased by $0.8 \mathrm{nmol}$ i.c.v. of the $5-\mathrm{HT}_{1 \mathrm{~A}}$ receptor antagonist, WAY 100635.

We can explain the effect observed with WAY 100635 by assuming that this compound antagonizes $5-\mathrm{HT}_{1 \mathrm{~A}}$ presynaptic receptors by increasing the amphetamine-induced 5-HT release. Very similar results were observed with benzylamine in the presence of the same pretreatments. The effect of the presynaptically acting 5-HT receptor antagonist, WAY 100635, is consistent with recent data (Grignaschi et al., 1998) obtained with different serotoninergic anorectic compounds, and provides further evidence that a part of the hypophagic activity of amphetamine and benzylamine could be serotoninergic.

In the light of the results of experiments on motor behavior, the major difference between amphetamine and benzylamine is the absence of central stimulatory effects for the latter compound. Relevant literature suggests that the hyperactivity and motor incoordination induced by amphetamine are mainly due to dopamine receptors (Cole, 1978; Aulakh et al., 1988) primarily located in the nigrostriatal and mesolimbic systems. The observation that, in $\alpha$-methyl- $p$-tyrosine-pretreated mice, the motor stimulatory effect induced by amphetamine was abolished confirms a dominant dopaminergic activity for this compound, which seems of minor importance for benzylamine, and indicates that substantial dopamine depletion was obtained after $\alpha$-methyl-p-tyrosine pretreatment. The reason for the discrepancy between the anorectic and motor stimulatory activities observed with amphetamine and benzylamine cannot be explained on the basis of the present experiments. It is possible that some differences exist with regard to the central brain region which controls feeding behavior or motor activity, and related receptor types indirectly stimulated by these two compounds at the doses used in our experiments.

In summary and conclusion, we have now described the anorectic activity of benzylamine, which seems to be partly due to a release of 5-HT. In terms of the response to amine oxidase inhibition and receptor antagonism it appears comparable to the effect of amphetamine. Our results provide an in vivo experimental demonstration that selective inhibitors of peripheral semicarbazide-sensitive benzylamine oxidases be of therapeutic value through increasing the pharmacological effects of one of the best substrates of these enzymes.

\section{Acknowledgements}

The authors wish to thank Prof. Franca Buffoni for her critical revision of the manuscript and the Marrion Merrel Dow Research Institute (Strasbourg Cedex, France) for the generous gift of MDL 72274. This work was partially supported by a grant from the Ministero Ricerca Scientifica, COFIN 1998.

\section{References}

Abdallah, A.H., Roby, D.M., Boeckler, W.H., Riley, C.C., 1976. Role of dopamine in the anorexigenic effect of dita; comparison with Damphetamine. Eur. J. Pharmacol. 40, 39-44.

Alemany, L., Olmos, G., Garcia-Sevilla, J.A., 1995. The effects of phenelzine and other monoamine oxidase inhibitor antidepressants on brain and liver $\mathrm{I}_{2}$ imidazoline-preferring receptors. Br. J. Pharmacol. 114, 837-845.

Aulakh, C.S., Hill, J.L., Wozniak, K.M., Murphy, D.L., 1988. Fenfluramine-induced suppression of food intake and locomotor activity is differently altered by the selective type A monoamine oxidase inhibitor clorgyline. Psychopharmacology 95, 313-317.

Banchelli, G., Buffoni, F., Elliot, J., Callingham, B.A., 1990. A study of the pharmacology of 3,5-ethoxy-4-aminomethylpyridine (B24), a novel amine oxidase inhibitor with selectivity for tissue semicarbazide-sensitive amine oxidase enzymes. Neurochem. Int. 17 (2), 215-221.

Banchelli, G., Pirisino, R., Ignesti, G., Raimondi L., Buffoni, F., 1994. In vivo effects of (E)-2-phenyl-3-chloroallylamine (MDL 72274) on amine oxidase activities in the rat. Personal communication, D.01 (35) 6th Amine Oxidase Workshop and 5th Trace Amine Conference, 31 July-3 August, Saskatoon, Saskatchewan, Canada.

Banchelli, G., Raimondi, L., Ghelardini, C., Pirisino, R., Bertini, V., De Munno, A., Lucchesini, F., 2000. Benzylamine-related compounds stimulate rat vas deferens neurotransmission and potentiate memory in the mouse acting as $\mathrm{K}^{+}$channel blockers. Pharmacol. Res. 41 (2), $151-162$.

Boor, P.J., Nelson, T.J., 1980. Allylamine cardiotoxicity: III. Protection by semicarbazide and in vivo derangements of monoamine oxidase. Toxicology 18, 87-102.

Buffoni, F., 1993. Properties, distribution and physiological role of semicarbazide-sensitive amine oxidases. Curr. Top. Pharmacol. 2, 33-50.

Buffoni, F., 1995. Semicarbazide-sensitive amine oxidase: some biochemical properties and general considerations. Prog. Brain Res. 106, 323-331.

Castillo, V., Lizcano, J.M., Visa, J., Unzeta, M., 1998. Semicarbazidesensitive amine oxidase (SSAO) from human and bovine cerebrovascular tissues: biochemical and immunological characterization. Neurochem. Int. $33(5), 415-423$.

Cole, S.O., 1978. Brain mechanisms of amphetamine-induced anorexia, locomotion and stereotypy: a review. Neurosci. Behav. Rev. 2, 89100

Cook, N.S., Quast, U., 1990. Potassium channel pharmacology. In: Cook, N.S. (Ed.), Potassium Channels: Structure, Classification, Function and Therapeutic Potential. Ellis Horwood, Chichester, pp. 181-255.

Currie, P.J., Coscina, D.V., Fletcher, P.J., 1998. Reversal of fenfluramine and fluoxetine anorexia by $8-\mathrm{OH}-\mathrm{DPAT}$ is attenuated following raphe injection of 5,7-dihydroxytryptamine. Brain Res. 800, 62-68.

Curzon, G., Gibson, E.L., Oluyami, A.O., 1997. Appetite suppression by commonly used drugs depends on 5-HT receptors but not on 5-HT availability. TIPS 18, 21-25.

Dawson, L.A., Routledge, C., 1995. Differential effects of potassium channel blockers on extracellular concentrations of dopamine and 5-HT in the striatum of conscious rats. Br. J. Pharmacol. 116, $3260-3264$. 
Deng, Y., Boomsma, F., Yu, P.H., 1998. Deamination of methylamine and aminoacetone increases aldehydes and oxidative stress in rats. Life Sci. 63, 2049-2058.

Elliot, J., Callingham, B.A., 1991. Effect of benzylamine and its metabolites on the responses of the isolated perfused mesenteric arterial bed of the rat. J. Auton. Pharmacol. 11, 323-335.

Finnegan, T.K., Irwin, I., Delanney, L.E., Langston, W., 1995. Age-dependent effects of the 2'-methyl analog of 1-methyl-4-phenyl-1,2,3,6tetrahydropyridine: prevention by inhibitors of monoamine oxidase B. J. Pharmacol. Exp. Ther. 273, 716-720.

Ghelardini, C., Galeotti, N., Pecori Vettori, A., Capaccioli, S., Quattrone, A., Bartolini, A., 1997. Effect of $\mathrm{K}^{+}$channel modulation on mouse feeding behaviour. Eur. J. Pharmacol. 329, 1-8.

Gray, N.M., Lu, M.C.H., Bhargava, H.N., 1981. The effects of stereoisomers of 2-and 9-aminobenzobornenes on food intake, brain serotonin concentration and monoamine oxidase activity in the rat. J. Pharmacol. Exp. Ther. 221, 58-62.

Gregory, L.W., Smith, G.C., 1982. Anorectic properties of three monoamine oxidase inhibitors. Pharmacol. Biochem. Behav. 17, $1135-1139$.

Grignaschi, G., Invernizzi, R.W., Fanelli, E., Fracasso, C., Caccia, S., Samanin, R., 1998. Citalopram-induced hypophagia is enhanced by blockade of 5- $\mathrm{HT}_{1 \mathrm{~A}}$ receptors: role of $5-\mathrm{HT}_{2 \mathrm{C}}$ receptors. Br. J. Pharmacol. 124, 1781-1787.

Haley, T.J., McCormick, G.L., 1957. Pharmacological effects produced by intracerebral injections of drugs in the conscious mouse. Br. J. Pharmacol. Chemother. 12, 12-15.

Knoll, J., 1998. (-)Deprenyl (Selegiline), a catecholaminergic activity enhancer (CAE) substance acting in the brain. Pharmacol. Toxicol. $82,57-66$.

Lewinson, R., Bohm, H.K, Glover, V., Sandler, M., 1978. A benzylamine oxidase distinct from monoamine oxidase B. Widespread distribution in man and rat. Biochem. Pharmacol. 27, 1857-1863.
Lyles, G.A., Marshall, C.M.S., McDonald, I.A., Bey, P., Palfreyman, M.G., 1987. Inhibition of rat aorta semicarbazide-sensitive amine oxidase by 2-phenyl-3-haloallylamines and related compounds. Biochem. Pharmacol. 37 (17), 2847-2853.

Moreley, J.E., Levine, A.S., 1985. The pharmacological eating behavior. Annu. Rev. Pharmacol. Toxicol. 25, 127-146.

Parada, M.A., Hernandez, L., Shwartz, D., Hoebel, B.G., 1988. Hypothalamic infusions of amphetamine increase serotonin, dopamine and norepinephrine. Physiol. Behav. 44, 607-610.

Parada, M.A., Hernandez, L., Degoma, E., 1992. Serotonin may play a role in the anorexia induced by amphetamine injections into the lateral hypothalamus. Brain Res. 577, 218-225.

Pirisino, R., Banchelli, G., Ignesti, G., Mantelli, L., Matucci, R., Raimondi, L., Buffoni, F., 1993. Calcium modulatory properties of 2,6-dibutylbenzylamine (B25) in rat isolated vas deferens, cardiac and smooth muscle preparations. Br. J. Pharmacol. 109, 1038-1045.

Ramos, K., Grossmann, S.L., Cox, L.R., 1988. Allylamine-induced vascular toxicity in vitro: prevention by semicarbazide-sensitive amine oxidase inhibitors. Toxicol. Appl. Pharmacol. 95, 61-71.

Schechter, L.E., 1997. The potassium channel blockers 4-aminopyridine and tetraethylammonium increase the spontaneous basal release of $\left[{ }^{3} \mathrm{H}\right]$ 5-hydroxytryptamine in rat hippocampal slices. J. Pharmacol. Exp. Ther. 282, 262-270.

Shucla, R., MacKenzie, D., Rech, R.H., 1990. Evidence for 5-HT receptor mediation in quipazine anorexia. Psychopharmacology 100, $115-118$

Vaught, J., Pelley, K., Costa, L.G., Sether, P., Enna, S.J., 1985. A comparison of the antinociceptive responses to GABA-receptor agonists THIP and baclofen. Neuropharmacology 24, 211-216.

Yu, P.H., Dong-mei Zuo, T., 1993. Oxidative deamination of methylamine by semicarbazide-sensitive amine oxidase leads to cytotoxic damage in the endothelial cells. Diabetes 42, 594-603. 